DOI: http://dx.doi.org/10.12957/demetra.2014.7973

\title{
Perspectivas do fornecimento de produtos da agricultura familiar para os equipamentos públicos de segurança alimentar e nutricional no Distrito Federal
}

\author{
Supply perspectives of family farmers products for food and nutrition security public facilities in the Federal \\ District, Brazil
}

Giselle Silva Garcial

Elisabetta Recinel

' Departamento de Nutrição, Faculdade de
Ciências da Saúde. Universidade de Brasília.
Brasília, DF, Brasil.

Correspondência / Correspondence

Elisabetta Recine

E-mail: recine@unb.br

\section{Resumo}

O aumento da disponibilidade de gêneros alimentares, por meio da consolidação de circuitos locais de produção e consumo, fortalece o cenário de um sistema agroalimentar descentralizado e de origem familiar capaz de promover a Segurança Alimentar e Nutricional (SAN). A fim de verificar a tendência de inserção desse modelo produtivo nas compras institucionais dos equipamentos públicos de Segurança Alimentar e Nutricional no Distrito Federal, foram entrevistados cinco atores sociais envolvidos: gestores públicos, representante local dos agricultores familiares, organização não governamental que recebe doação do Banco de Alimentos e empresa fornecedora de refeições para os restaurantes comunitários. Os resultados foram analisados a partir do discurso do sujeito coletivo (DSC) com o auxílio do software QualiQuantiSoft ${ }^{\oplus}$ versão 1.3c Build (2). Foram muitos os obstáculos apontados para implementação da agricultura familiar no mercado institucional do Distrito Federal, tais como burocracias e hegemonia da agroindústria. Também foram apontadas, no entanto, alternativas de superação, como a estruturação e organização produtiva dos agricultores para atender às demandas institucionais; ações de sensibilização aos empresários atuantes nos equipamentos, junto a uma política de inserção da compra preferencial da agricultura familiar nos editais de licitação dos restaurantes comunitários; além da oferta de infraestrutura local para escoamento mais eficiente da produção familiar. Observou-se um ambiente favorável, mas que só se concretizará com o envolvimento de toda a comunidade e o apoio do governo do Distrito Federal. 
Palavras-chave: Abastecimento de Alimentos. Agricultura Sustentável. Programas e Políticas de Nutrição e Alimentação. Segurança Alimentar e Nutricional. Nutrição em Saúde Pública.

\section{Abstract}

The increase of the availability of foodstuff, through the consolidation of local production and consumption circuits, strengthens the scenario of a decentralized agri-food system of family origin capable of promote Food and Nutrition Security (SAN). Aiming to verify the tendency of insertion of this model of production in institutional purchases of public equipment of Food and Nutrition Security in the Federal District, Brazil, five social actors have been interviewed: public managers, local family farmers representative, non-governmental organization that receives donation from Food Bank and meal supplier to community restaurants. Results were analyzed based on the discourse of the collective subject (DSC) using the Qualiquantisoft ${ }^{\circledR}$ version $1.3 \mathrm{c}$ Build (2) software. Many obstacles to the deployment of family farming in the institutional market of the Federal District were pointed, such as bureaucracy and hegemony of agribusiness. However, alternatives to overcome problems were identified, such as productive structuring and organization of farmers to achieve institutional demands; actions to raise awareness directed to businessmen acting in equipment, along with policy of inclusion of preferential purchase from family farming to community restaurants in bidding documents; altogether with the offer of local infrastructure for more efficient family production flow. Favorable environment has been observed, but it will only be achieved with the involvement of the whole community and support of the Federal District government.

Key words: Food Supply. Sustainable Agriculture. Nutrition Programs and Policies. Food Security. Nutrition, Public Health.

\section{Introdução}

Observa-se, ainda hoje, um número relevante de indivíduos em situação de fome ou com alimentação precária, o que não condiz com o volume mundial de alimentos produzidos, maior a cada ano. Essa contradição pode ser entendida por meio da reflexão proposta por Josué de Castro, que já afirmava: "o fenômeno da fome não é consequência da superpopulação ou 
decorrente de questões climáticas ou raciais, mas um flagelo construído pelos homens em suas opções políticas e econômicas". ${ }^{1}$

Essa interpretação sociopolítica da fome acelerou e potencializou a construção de políticas públicas voltadas à Alimentação e Nutrição no Brasil, ${ }^{2}$ incorporando o conceito de Segurança Alimentar, restrito, até meados dos anos 90, ao caráter biológico e higiênico-sanitário dos alimentos.

Em 1996, os países reunidos na Cúpula Mundial da Alimentação, em Roma, divulgaram a incorporação da noção de acesso a alimentos seguros, de qualidade nutricional, produzidos de forma sustentável, equilibrada e culturalmente aceitável, dando origem ao conceito de Segurança Alimentar e Nutricional.,3

O conceito atualmente adotado no Brasil foi definido em 2004, na II Conferência Nacional de Segurança Alimentar e Nutricional realizada em Olinda, Pernambuco. ${ }^{3}$ Em 2006, a Lei no 11.346 , que estabeleceu o Sistema Nacional de Segurança Alimentar e Nutricional (SISAN), adotou a mesma definição, sendo Segurança Alimentar e Nutricional (SAN):

[...] a realização do direito de todos ao acesso regular e permanente a alimentos de qualidade, em quantidade suficiente, sem comprometer o acesso a outras necessidades essenciais, tendo como base práticas alimentares promotoras de saúde que respeitem a diversidade cultural e que sejam ambiental, cultural, econômica e socialmente sustentáveis. ${ }^{4}$

Está previsto no SISAN um modelo de política pública intersetorial que requer, para sua implementação e execução, o envolvimento de diversos setores governamentais e não governamentais. Neste sentido, a Câmara Interministerial de Segurança Alimentar e Nutricional (CAISAN) coordenou e elaborou, em parceria com o Conselho Nacional de Segurança Alimentar e Nutricional (CONSEA), o Plano Nacional de Segurança Alimentar e Nutricional (PLANSAN), que se constitui como ferramenta de planejamento, gestão e execução da Política Nacional de Segurança Alimentar e Nutricional (PNSAN). ${ }^{5}$

Seguindo esse mesmo processo, o Distrito Federal aderiu ao SISAN em 7 de novembro de 2011, na IV Conferência Nacional de Segurança Alimentar e Nutricional (CNSAN), ocasião em que firmou o compromisso de elaborar o I Plano Distrital de Segurança Alimentar e Nutricional (I PDSAN), que traz em uma de suas diretrizes o incentivo à promoção do abastecimento e estruturação de sistemas sustentáveis e descentralizados, de base agroecológica, de produção, extração, processamento, distribuição e comercialização de alimentos, além do fomento à produção e à agroindústria de base familiar. Com estas diretrizes, o I PDSAN foi lançado no dia 23 de outubro de 2013, ${ }^{6}$ durante o I Encontro de Segurança Alimentar e Nutricional do Distrito Federal. 
A agricultura de base familiar é o modelo de produção que promove a estruturação de circuitos locais de produção e consumo, facilitando o acesso a alimentos adequados e saudáveis, inclusive sendo uma fornecedora fundamental para o abastecimento de alimentos das grandes cidades. ${ }^{7}$

No Brasil, o censo agropecuário demonstra em termos estatísticos a relevância dessa forma de produção no país. Os dados apresentam que $76,8 \%$ do feijão preto; $83,8 \%$ do feijão fradinho; $86,7 \%$ da mandioca; $55,0 \%$ do café; $58,0 \%$ do leite de vaca; $67,0 \%$ do leite de cabra; $50,0 \%$ das aves e 59,0\% dos suínos produzidos no país têm origem na produção familiar. ${ }^{8}$

O cenário do Distrito Federal é diferente do expresso em nível nacional. Os resultados apontam, para os mesmos produtos, um percentual até 70 vezes inferior: $1,2 \%$ de feijão preto; $8,1 \%$ do feijão fradinho; $43,0 \%$ da mandioca; $11,0 \%$ do café; $17,4 \%$ do leite de vaca; $6,1 \%$ do leite de cabra; $5,0 \%$ das aves e 7,6\% dos suínos - revelando uma participação incipiente da agricultura familiar para a produção total de alimentos no território. ${ }^{8}$

Contudo, a distribuição fundiária do DF assemelha-se à nacional. Observa-se, no âmbito distrital, uma participação de $80 \%$ da agricultura familiar em relação ao total de estabelecimentos produtores, sendo detentora de apenas $14 \%$ da área total de terras agricultáveis. No âmbito nacional, os mesmos valores correspondentes são de $78 \%$ e 13\%, evidenciando uma geral desigualdade de distribuição fundiária. ${ }^{8}$

Uma forma de minimizar essas desigualdades e distorções identificadas no processo produtivo é ampliando e fortalecendo políticas que fomentem a produção familiar e ampliem suas oportunidades de comercialização. Algumas políticas e programas nacionais foram elaborados para tal. O Programa de Fortalecimento da Agricultura Familiar (PRONAF) foi o primeiro deles, criado em 1995, e tem como objetivo reduzir a escassez de créditos existentes para os pequenos agricultores rurais do país. ${ }^{9}$

Os resultados já começam a se manifestar, diante de anos de existência do Programa. O PRONAF alcançou ampla dimensão, estendendo-se de forma considerável por todo o território nacional, ampliando o montante financeiro, desenvolvendo programas especiais para atender às diversas categorias de agricultores familiares, assumindo a assistência técnica e reforçando a infraestrutura nos municípios de alcance. ${ }^{9}$

Entretanto, apesar do crescimento notável do Programa, ele apresenta fragilidades. Uma das principais é o suposto desvio de foco observado na sua gestão, que tem direcionado maiores investimentos aos agricultores considerados "detentores de uma produção segura", aqueles produtores familiares de soja e fumo, gêneros alimentares tradicionalmente encontrados na agroindústria, em detrimento daqueles agricultores produtores de arroz e feijão, que são os alimentos produzidos para o mercado e o consumo internos. ${ }^{9}$ 
Após a criação do PRONAF, o Programa de Aquisição de Alimentos (PAA), criado em 2003 pelo Governo Federal, ganhou destaque, tendo como atributo compor mais uma estrutura de combate à fome e à pobreza. Surgiu para fortalecer a agricultura familiar brasileira, incentivando a aquisição governamental de produtos hortifrutigranjeiros de base familiar, a fim de que fossem, inclusive, distribuídos para pessoas em estado de vulnerabilidade social e insegurança alimentar e nutricional. ${ }^{10}$

O PAA, portanto, se propõe a enfrentar o principal desafio dos agricultores familiares: a comercialização. Nesse sentido, o programa articula as políticas públicas correlacionadas com a agricultura familiar, além de trazer para o debate aspectos ambientais, sociais, históricos, políticos e econômicos ligados a essa forma de produção. ${ }^{10}$

Na dimensão distrital, surge o Programa de Aquisição da Produção da Agricultura Familiar do Distrito Federal (PAPA/DF), que segue, da mesma forma, a lógica do incentivo. O PAPA-DF garante a aquisição direta, por dispensa de licitação, de produtos produzidos por agricultores familiares rurais e urbanos, e demais beneficiários e organizações que se enquadrem nas disposições da Lei Federal no 11.326, de 24 de junho de 2006, bem como povos e comunidades tradicionais e os beneficiários da reforma agrária", tendo em vista atender às instituições sócio-assistenciais; os programas e projetos públicos de Segurança Alimentar e Nutricional; e o mercado governamental. ${ }^{11}$

Ambos, PAA e PAPA-DF, incorporaram em suas formas de execução a ideia de que criar ações de incentivo à aquisição institucional dos produtos da agricultura familiar é a medida inicial a ser tomada para alavancar a implementação e o crescimento dessa forma de produção no Brasil e no Distrito Federal, a fim de ampliar seu poder comercial.

A Política Nacional de Alimentação Escolar (PNAE) incorporou esse pensamento, recomendando que a compra de no mínimo 30\% dos recursos federais repassados do fundo de educação para as escolas fossem direcionados para a aquisição de gêneros da agricultura familiar. ${ }^{12}$

Os benefícios dessa política são apontados no estudo desenvolvido por Belik \& Chaim, ${ }^{13}$ o qual aponta que o desenvolvimento local é favorecido com o aumento da aquisição de alimentos da agricultura familiar, havendo impulso na economia local, já que a conformação de um mercado institucional exige dos produtores certa organização para atender às demandas. Afirmam os autores: "dentro desta proposta de inclusão de produção local, o cardápio da alimentação escolar acaba resgatando a cultura alimentar regional e também promovendo ganhos em termos nutricionais e de qualidade". ${ }^{13}$

Diante dos resultados iniciais identificados no PNAE, iniciou-se a reflexão sobre as potencialidades e benefícios de se ampliar o mercado institucional para que os produtos da agricultura familiar se insiram em outros programas públicos. Tendo em vista viabilizar essa 
reflexão no âmbito do Distrito Federal, torna-se indispensável a participação do governo para incorporar a agricultura familiar em diversas dimensões e políticas, indo além da alimentação escolar, alcançando os programas e equipamentos públicos de provimento alimentar direto e promotores de SAN do DF, para assim fortalecer as cadeias produtivas curtas e promover uma alimentação verdadeiramente adequada e saudável.

Esta pesquisa tem, portanto, o objetivo de identificar a compreensão dos gestores públicos e organizações sociais relacionados aos equipamentos públicos de Segurança Alimentar e Nutricional do Distrito Federal, a respeito das potencialidades e desafios da inserção da agricultura familiar nos restaurantes comunitários e no banco de alimentos locais.

\section{Percurso metodológico}

Trata-se de pesquisa descritiva conduzida como estudo de caso, de abordagem quantiqualitativa, ${ }^{14}$ realizada em duas etapas. A primeira etapa consistiu de revisão de literatura sobre o tema, tendo por finalidade investigar a atual concepção do que são e como funcionam os circuitos curtos de produção e consumo, bem como as potencialidades e os desafios de inserção da agricultura familiar nos programas e equipamentos públicos de Segurança Alimentar e Nutricional existentes.

A segunda etapa, ocorrida de outubro de 2012 a janeiro de 2013, compreendeu a realização de entrevistas semiestruturadas com cinco atores sociais: dois gestores dos equipamentos públicos de Segurança Alimentar e Nutricional do Distrito Federal - banco de alimentos e restaurantes comunitários; dois atores relacionados aos equipamentos públicos (empresa fornecedora de refeições nos restaurantes comunitários e organização não governamental favorecida com doações do banco de alimentos); e um associado à organização de agricultores familiares local.

A seleção dos indivíduos foi consonante com a metodologia proposta por Minayo, ${ }^{15}$ que pressupõe a escolha daqueles que possuem opiniões mais significativas para o contexto social, possibilitando uma coleta de dados mais fidedigna. Os entrevistados selecionados estão inseridos no contexto da promoção de Segurança Alimentar e Nutricional e, portanto, se constituem como grupo representativo, o que permite analisar a "lente perceptiva" desses atores sociais.

O roteiro de entrevista semiestruturado é a ferramenta ideal, porque ao mesmo tempo que facilita uma abordagem segura, já que é previamente elaborado, não enquadra as respostas em perguntas específicas, ou seja, possibilita ao entrevistado uma reflexão sobre os vários aspectos trazidos pelo tema, garantindo ao pesquisador uma maior riqueza e profundidade das informações

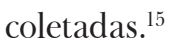


A ferramenta utilizada foi comum a todos os sujeitos, permitindo padronização da análise para todas as entrevistas. O questionário foi dividido em três blocos temáticos: Bloco da Segurança Alimentar e Nutricional, Bloco do Circuito Curto de Produção e Agricultura Familiar e o Bloco do Mercado Institucional - Potencialidades e Desafios. O questionário teve por finalidade investigar sob a ótica dos gestores e entidades sociais relacionadas, bem como o próprio segmento de agricultores familiares, a aceitação, a viabilidade e os obstáculos para a estruturação de circuitos curtos de produção, vinculando a agricultura familiar aos equipamentos públicos do Distrito Federal.

Com o objetivo de minimizar possíveis erros e vieses no estudo, elaborou-se um "Protocolo para Realização da Entrevista", que teve como finalidade prever erros frequentemente cometidos por pesquisadores na realização de entrevista para pesquisa qualitativa, apontados por Rosa \& Arnoldi. ${ }^{16}$

A saída de campo foi realizada conforme as etapas: apresentação do objetivo do estudo, leitura do Termo de Consentimento Livre e Esclarecido (TCLE), apresentação da credencial institucional e conversa inicial. As entrevistas foram gravadas, com a autorização dos indivíduos entrevistados, por meio da assinatura do TCLE, aceito e aprovado pelo Comitê de Ética em Pesquisa com Seres Humanos da Universidade de Brasília (Parecer n⿳0 150/12).

As entrevistas foram degravadas e analisadas, resgatando as opiniões relevantes por meio do processo que engloba: identificação de expressões-chave e ideias centrais. A expressão-chave se constitui como o trecho que melhor representa o conteúdo do discurso; e as ideias centrais, por descreverem o sentido presente, dão origem às categorias discursivas. ${ }^{17}$

As expressões-chave, ideias centrais e categorias discursivas foram transferidas para o software QualiQuantiSoft ${ }^{\circledR}$ versão 1.3c Build (2), que permitiu a construção dos DSC (discursos do sujeito coletivo). Os discursos foram construídos por meio do somatório das expressões-chave de todas as repostas para cada categoria relevante. Dessa maneira, permitiram o entendimento das percepções do grupo entrevistado sobre o tema, caracterizados como a representação do pensamento coletivo.

\section{Resultados e discussão}

O roteiro de entrevista foi composto por três blocos temáticos: (i) Segurança Alimentar e Nutricional; (ii) Circuito Curto de Produção e Agricultura Familiar; e (iii) Mercado Institucional - Potencialidades e Desafios. Após as degravações e posterior análise das entrevistas, o roteiro foi reorganizado de forma a condensar os discursos por "categorias temáticas”: compreensão da SAN - produção e consumo de alimentos; sistema alimentar - produção familiar, compras públicas e potencialidades; os desafios; e por fim, as propostas para superação dos obstáculos. 


\section{Compreensão da SAN: produção e consumo de alimentos}

Os entrevistados foram convidados a refletir sobre as dimensões contempladas no conceito de Segurança Alimentar e Nutricional atualmente adotado no Brasil, bem como fazer um paralelo dessas dimensões com o atual cenário de produção e consumo de alimentos.

O discurso coletivo permite inferir que os entrevistados valorizam fortemente uma alimentação variada para que possa ser classificada como "Alimentação Saudável e Adequada", remetendo aos benefícios trazidos para a saúde. Acreditam que uma forma de garantir a Segurança Alimentar e Nutricional é a valorização de um hábito alimentar voltado ao consumo de hortaliças e frutas na alimentação, lembrando ainda de temas atuais em debate, como o uso indiscriminado de agrotóxicos nas lavouras.

DSC: [...] Eu entendo que o conceito de Segurança Alimentar ele é amplo. No conceito convencional Segurança Alimentar e Alimentação Saudável é aquela que tem uma Certificação Alimentar. A gente procura sempre... a melhor forma de qualidade, em questão de variedade dos alimentos, acesso à alimentação adequada, foco na busca de alimento saudável. Não é só a questão de matar a fome, é a questão de você saber nutrir o seu corpo pra que você não tenha determinadas doenças e também doenças associadas, que a gente sabe que pode ocasionar. Mudanças de hábito focada muito no aumento do consumo de frutas, verduras e legumes. A qualidade é um tema interessante também porque envolve uma questão bastante em debate hoje, que são resíduos de agrotóxicos. [...]

Este entendimento está em consonância com a dimensão nutricional da SAN, a qual prevê a escolha e o consumo de alimentos saudáveis e adequados, a fim de promover saúde. Como alimentação adequada, entende-se que são alimentos apropriados para os padrões alimentares, inclusive livres de substâncias adversas em níveis superiores aos preestabelecidos pela legislação nacional e pelos padrões internacionais. Como exemplos estão as toxinas, os poluentes resultantes de processos agrícolas e industriais e os resíduos de drogas veterinárias (indutoras de crescimento e hormônios). ${ }^{3}$

A segunda categoria mais comentada foi "processos educativos" $(n=4)$, traduzidos como Educação Alimentar e Nutricional (EAN). A maioria dos entrevistados acredita que para se garantir SAN é necessário partir de orientações de mudanças de hábitos alimentares, além da agricultura tradicional para uma agricultura sustentável, a fim de contemplar o respeito pelo ambiente e pelas relações sociais. 
DSC: [...] A promoção tá muito, ao meu ver, orientada às questões de reeducação alimentar, de mudanças de hábito. A principal tarefa é o processo de educação e capacitação. Educação Alimentar e Nutricional e Educação Ambiental, orientada à conversão da agricultura tradicional nos assentamentos, nas comunidades da agricultura familiar, numa agricultura sustentável com o uso de práticas adequadas à questão da preservação do solo, à preservação das fontes, à recuperação de áreas degradadas, à utilização de sementes crioulas pra evitar o transgênico. [...]

A capacitação, apontada pelos entrevistados como ação estratégica, pode ser enquadrada dentro do conceito de EAN como uma forma de "recurso educacional ativo". Segundo o Marco de Referência de Educação Alimentar e Nutricional para as Políticas Públicas, publicado em 2012:

EAN, no contexto da realização do Direito Humano à Alimentação Adequada e da garantia da Segurança Alimentar e Nutricional, é um campo de conhecimento e de prática contínua e permanente, transdisciplinar, intersetorial e multiprofissional que visa promover a prática autônoma e voluntária de hábitos alimentares saudáveis. A prática da EAN deve fazer uso de abordagens e recursos educacionais problematizadores e ativos que favoreçam o diálogo junto a indivíduos e grupos populacionais, considerando todas as fases do curso da vida, etapas do sistema alimentar e as interações e significados que compõem o comportamento alimentar". ${ }^{18}$

Quanto ao atual sistema produtivo, a totalidade dos entrevistados acredita que há uma agressão às dimensões contempladas no conceito de Segurança Alimentar e Nutricional. Dessa maneira, para haver maior aprofundamento dos discursos, a categoria "Não contempla as dimensões de SAN" foi dividida em subcategorias: "Não. Devido à dificuldade de acesso" (n=3); "Não. Devido aos hábitos alimentares atuais" (n=3); "Não. Devido às questões de sustentabilidade" (n=3); "Não. Devido à utilização de agroquímicos" $(n=4)$; e "Não. Devido ao desconhecimento da origem produtiva" ( $\mathrm{n}=1)$. As quatro primeiras categorias foram as mais respondidas.

DSC: [...] A gente ainda tem muitas temáticas que ainda precisam evoluir na questão da qualidade dos alimentos, do próprio acesso. Temos do produtor ao fornecedor uma caminhada muito grande, se perde muito na estrada, nesse caminho tem grandes desperdícios de alimentos. Nós também temos muitos alimentos desaparecidos, porque o agronegócio transformou este alimento numa commoditie ou num sistema de produção que tirou ele daqui. [...] (grifo nosso).

Os entrevistados identificam o acesso como um dos atuais entraves do sistema produtivo para contribuir na garantia de SAN. A atual forma de abastecimento alimentar das cidades ocorre por meio do transporte de alimentos por longos trajetos, o que desencadeia aumento no preço dos produtos, além de contribuir para o aumento do desperdício. Para Maluf, ${ }^{19}$ o apoio aos circuitos 
regionais de produção e distribuição desencadeia a criação de oportunidades de trabalho e renda para os pequenos agricultores locais, ao passo que valoriza alimentos regionais e diferenciados, tendo impacto positivo nos custos, pelo barateio do transporte ${ }^{19}$ e, também, no consumo de alimentos com maior qualidade.

O hábito alimentar atual também é um fator determinante apontado para a insegurança alimentar e nutricional. O consumo do brasileiro hoje perpassa pelo hábito de ingestão de alimentos não saudáveis e altamente calóricos. Os dados da POF-2008/2009 (Pesquisa de Orçamento Familiar) revelam que os alimentos marcadores de uma alimentação não saudável, rica em açúcares, gorduras e sódio, são os fast food, doces (biscoitos recheados) e os refrigerantes, e estão associados aos maiores valores de consumo energético da população. ${ }^{20}$

DSC: [...] a grande maioria da população, ao invés de comer uma salada, pede um hambúrguer, ao invés de comer uma tapioca, pede um recheado. Hábitos alimentares de consumir muito alimento fora de casa, de consumir muito fast food. Somos ainda muito influenciados pela propaganda enganosa e publicidade excessiva de um alimento com teor excessivo de sódio, de gordura nos alimentos. [...]

DSC: [...] O hábito do povo brasileiro, que não é diferente do DF, é um hábito convencional. O hábito histórico do desmatamento, o hábito histórico do descuido com a natureza, tanto com a fonte da água, quanto com o solo, com a flora e a fauna. [...]

DSC: [...] tem produtos químicos de toda a diversidade pra inflar o frango e ele chegar na mesa o mais rápido possível, pra garantir o retorno econômico. Tem a grande quantidade, mas que não preza pela qualidade. Pra nós o alto grau, o alto índice de agroquímico compromete a saúde do produto e compromete a saúde de quem o ingere. [...]

Para enfatizar o discurso a respeito da temática "agrotóxico", trazida pelos entrevistados, esta foi categorizada em separado da questão "sustentabilidade". A Abrasco, debruçada no combate desse veneno, elaborou o dossiê Um alerta sobre os impactos dos agrotóxicos na saúde, com o intuito de orientar a população sobre a preocupação expressa de "enfrentar a insegurança alimentar e nutricional, por meio da reprimarização da economia, a fim de repensar a expansão das fronteiras agrícolas para exportação de commodities, e a questionar o modelo de modernização agrícola conservadora e da monocultura químico-dependente. ${ }^{21}$

O mesmo documento indica, de forma consonante com o expresso no DSC, que:

[...] as culturas de exportação, monoculturas de soja, milho, algodão, eucalipto e cana-de-açúcar, vêm ocupando cada vez mais terras agricultáveis, com intuito de alimentar apenas o ciclo de agrocombustíveis, celulose, ferro-aço, ao invés de pessoas, avançando sobre o bioma do cerrado e da Amazônia, impondo limites à forma de vida e de produção da agricultura camponesa. ${ }^{21}$ 
O dossiê traz informações do período de 2002 a 2011, o qual demonstra que os alimentos consumidos cotidianamente pelos brasileiros, como arroz, feijão e mandioca, ocupam a mesma área de produção, enquanto que as monoculturas de milho, soja, algodão e sorgo expandiram suas áreas de produção e exportação, processo simultâneo a um aumento exponencial do número de agroquímicos utilizados. Essa situação vai de encontro à regulamentação do uso de agrotóxicos e, muitas vezes, é sustentada por pesquisas científicas que são induzidas a renegar as nocividades possíveis e os efeitos negativos à saúde, ao meio ambiente e à segurança alimentar e nutricional. ${ }^{21}$

\section{Sistema Alimentar: produção familiar, compras públicas e potencialidades}

Nesse campo dos discursos, os entrevistados manifestaram suas ideias a respeito da agricultura familiar e sua contribuição para a garantia de SAN; seus conhecimentos a respeito de propostas federais ou distritais que promovam a aquisição preferencial de alimentos da agricultura familiar; sobre a importância de legislação para o fomento desta forma produtiva; e as potencialidades de se garantir um mercado institucionalizado no Distrito Federal (restaurantes comunitários e banco de alimentos) para a agricultura familiar.

A maioria dos entrevistados acredita que os motivos pelos quais a produção familiar dialoga com as dimensões abarcadas no conceito de SAN são "a grande capacidade de promover a valorização social e econômica do produtor" e "a forte relação dessa cadeia produtiva com a sustentabilidade ambiental, social, cultural e econômica”, observadas nos discursos a seguir.

DSC: [...] Eu acredito que tá em consonância total esse tipo de ação de circuito curto local [...] ele favorece nesse sentido de construir, de fortalecer, essa contracultura na alimentação. E eu acho que a gente só tem a ganhar, se resgatar um sistema de produção e consumo mais eficiente, mais lógico, que tem impactos sociais muito fortes. [...]

DSC: [...] Eu acredito que sim, desde que sejam incorporadas práticas sustentáveis... se você mantém o sistema convencional de produção, e você cria o circuito curto de produção, você apenas introduziu uma novidade. Você introduziu uma coisa boa, mas a base permanece a do agronegócio. [...]

O pensamento descrito é compatível com os resultados de um artigo publicado na revista Journal of Rural Studies, realizado no Reino Unido, por meio de entrevistas com indivíduos de cinco localidades distintas, sendo duas do meio rural e três do urbano. Os entrevistados declararam, por ordem de importância, os motivos que os conduzem à escolha dos alimentos, sendo: primeiro, a qualidade (gosto, alimento fresco e aparência); depois, a questão do acesso (custo e conveniência ou proximidade); e, com menor importância, a imagem (embalagem e marca do produto). ${ }^{22}$ 
No mesmo estudo, as questões relacionadas à saúde e ao bem-estar do animal e questões ambientais foram consideradas de elevada relevância, enquanto que a produção de orgânicos foi considerada de baixa relevância. Para os entrevistados da área rural, a maior preocupação concerne ao conhecimento da origem do produto e se o alimento é local. ${ }^{22}$

Pode-se observar que, tanto nos discursos do estudo citado, quanto nos DSC apresentados, a ideia de sustentabilidade está presente, o que ressalta o distanciamento do atual modelo produtivo, a fim de tornar a produção alimentar associativa aos preceitos da SAN. Sabe-se, entretanto, que para haver aproximação do modelo sustentável proposto, é necessário haver forte incentivo do Estado, que deverá ter papel mais expressivo no que concerne ao fomento, não apenas concedendo recursos, mas, de fato, diminuindo os empecilhos e as burocracias licitatórias encontradas pelo percurso.

Essa necessidade foi contemplada no estudo de Triches \& Schneider, ${ }^{23}$ segundo o qual, até 2009, os recursos utilizados em compras públicas deveriam ser obrigatoriamente licitados. Esse fato constituía importante entrave para a agricultura familiar se inserir no mercado dos programas públicos. O Estado, com seu dever de promover e facilitar o acesso a uma produção de cadeia agroalimentar vinculada à promoção de saúde e de qualidade nutricional, ${ }^{23}$ deve, portanto, desempenhar papel mais efetivo na coordenação e elaboração de revisões sistemáticas da legislação concernente.

A esse respeito, os entrevistados, de forma geral, acreditam que é necessário criar legislação recomendando a aquisição de produtos oriundos da agricultura familiar para os equipamentos públicos de SAN no Distrito Federal, mas que essa legislação tenha como finalidade realmente facilitar o acesso e consolidar o avanço.

DSC: [...] Isso é fundamental. Eu acho que a lei pode dar suporte [...] com certeza seria um incentivo. Mas é necessário que a sociedade fiscalize, no sentido assim de monitoramento. Tem que criar lei específica até pra amarrar essa questão do direito, porque se eu não amarro, fica solto. Numa perspectiva de con-so-li-da-ção pra que isso não retroceda. Na verdade, pra que essas mudanças legais, elas se transformem em políticas de Estado e não só em políticas de governo. [...]

Apenas um discurso manifestou ideia contrária: DSC: “[...] Eu acho que não seria nem necessário uma Lei (ênfase) pra isso, porque talvez isso aí você engessasse até a questão da oferta e da procura. [...]"

Os indivíduos foram questionados sobre seus conhecimentos acerca de programas federais ou distritais que recomendassem a compra de produtos oriundos da agricultura familiar. Foram obtidas 
ao todo nove respostas, categorizadas em "PNAE" (n=4); "PAA" (n=2); "PAPA/DF" (n=2); e "Não soube informar" ( $n=1)$. Oitenta por cento dos entrevistados referiram ter conhecimento sobre o PNAE.

DSC: [...] Existe o PNAE - Programa Nacional de Alimentação Escolar, que adota essa concepção: comprar da Agricultura Familiar sem licitação. A gente percebe que o Estado entendeu que é necessário atuar nesse campo de garantir que: o que for produzido na agricultura familiar e na reforma agrária, 30\%, 40\%, 50\%, pode chegar a 100, mas não pode ser menos que 30, possa ser comercializado para o atendimento das demandas públicas e formação de estoques na área da Segurança Alimentar. [...] (grifo nosso).

Triches \& Schneider ${ }^{23}$ afirmam que, após estudo prospectivo do PNAE, é possível avaliá-lo como: [...] grande potencial para uma política de caráter estruturante, já que possibilita a aquisição de gêneros alimentícios de produtores locais, gerando renda e beneficiando os pequenos agricultores. No entanto, no que se refere à efetivação dessa política no nível local, poucas iniciativas tinham sido observadas até a obrigatoriedade legal. ${ }^{23}$

Isso sustenta a hipótese de que a criação de leis seria fundamental para a inserção de uma nova cultura referente à relação entre produção de alimentos, sustentabilidade social, econômica e ambiental e Segurança Alimentar e Nutricional.

Pode-se inferir, dos resultados encontrados, que o PNAE foi o programa mais referenciado por ser o primeiro a realizar conexão de diferentes setores da política pública, como o campo do abastecimento da agricultura familiar (Ministério da Agricultura, Pecuária e Abastecimento) e a alimentação escolar (Ministério da Educação). É devido à intersetorialidade ${ }^{23}$ que o programa é tão popular e notável conforme observado.

No tocante a potencialidades e benefícios de uma política, programa ou ação com este perfil, os entrevistados avaliaram, de seus pontos de vista, a incorporação da agricultura familiar nos equipamentos públicos de SAN do Distrito Federal, os restaurantes comunitários e o banco de alimentos.

DSC: [...] O primeiro benefício que você que vai comprar, é você saber que aquele produto está sendo produzido por uma família de pessoas simples, mas que a partir daquela produção construiu a dignidade. E, as empresas, [que ocupam os Restaurantes Comunitários] trabalhando com um custo menor, pode vender por um preço menor [a refeição] e acaba beneficiando, de um modo geral, a todo mundo. A vantagem pros agricultores de programas desta natureza é a garantia de renda, de manter uma qualidade de vida, de tirar da situação de miséria, de proteger as gerações futuras. [...] (grifo nosso). 
Como pode ser observado, os discursos convergem para a categoria "melhoria das condições socioeconômicas do agricultor" ( $(n=5)$, a qual apresentou maior frequência de respostas. Foram mencionadas, ainda, questões como "qualidade nutricional nos equipamentos públicos" (n=4), a "facilidade na garantia do acesso" (n=4) e "mercado consumidor maior e seguro" $(n=4)$.

Já é consenso que o desenvolvimento e o fortalecimento da agricultura de base familiar e local garantem a melhoria da qualidade de vida no meio rural e criam condições sociais melhores para os produtores, que acabam por ter resgatadas a sua dignidade e cidadania. ${ }^{23-25}$

No Reino Unido, essa percepção de desenvolvimento social e econômico local é um quesito de ponderação no momento da aquisição de alimentos. Os consumidores relatam preferir comprar aqueles alimentos produzidos localmente de forma sustentável, econômica e ambiental ${ }^{22}$.

O estudo realizado por Starr et al. ${ }^{26}$ reforça que a inserção de produtos da pequena agricultura local fornece, aos equipamentos públicos de alimentação, alimentos de maior qualidade, além da possibilidade vantajosa de estarem associados às práticas educativas de alimentação e nutrição, refletindo no maior interesse por consumo de alimentos sazonais, frescos e culturais. ${ }^{26}$ Triches \& Schneider ${ }^{23}$ confirmam esse mesmo resultado: após a inserção da agricultura familiar na merenda escolar:

[...] houve uma maior frequência de recebimento de produtos frescos, com maior variedade, qualidade, além de melhora da aceitação das refeições. As crianças passaram a ingerir alimentos que antes não comiam, devido à melhor apresentação dos gêneros, como o milho e o tomate. ${ }^{23}$

\section{Os desafios}

Devido à identificação de inúmeras dificuldades e desafios, apontados por pesquisadores do tema e enfrentados pelos agricultores familiares, para conseguirem concorrer no mercado de alimentos e, sobretudo, para se inserirem nos mercados institucionais apontados pelos pesquisadores do tema, foi solicitado aos entrevistados que, segundo seus conhecimentos e rotinas de trabalho, identificassem quais desafios eles apontariam. As maiores convergências de respostas foram para as categorias "burocracia" $(n=5)$ e "hegemonia da agroindústria" $(n=4)$.

DSC: [...] A BU-RO-CRA-CI-A. Não é que não tenha que ter controle, mas isso dificulta nas Tomadas Públicas... Nem todo agricultor familiar tem uma organização burocrática. A burocracia toda com a qual o governo trabalha, dificulta muito quando tudo é licitado. [...]

DSC: [...] O sistema capitalista, esse sistema convencional... ele não tem interesse. Por que incentivar a agricultura familiar pra ela garantir, suprir, 100\% da necessidade do abastecimento alimentar, da Segurança Alimentar e Nutricional? Eu estaria incentivando o meu adversário na competição pelo lucro. Os pequenos agricultores ficam, então, prejudicados. [...] 
Os DSCs apontam que o governo e sua estrutura funcional são os grandes entraves para a real inserção dos agricultores familiares no mercado institucional de políticas e programas públicos garantidores de Segurança Alimentar e Nutricional. Tal resultado apresenta-se como uma contradição, já que o governo, em vista do reconhecimento da importância relevante que a pequena agricultura local e familiar tem em melhorar as condições sociais e econômicas e a qualidade de vida nas regiões urbanas e rurais, fundamentou leis no sentido de implementá-la no Programa de Alimentação Escolar, além de buscar diminuir as dificuldades licitatórias pela permissão da compra direta, como observado na Lei no 4.752, de 7 de fevereiro de 2012, que dispõe sobre o PAPA-DF.

A dificuldade apontada na prática pode ser associada à falta de informação sobre as novas leis vigentes, além de uma, ainda incipiente, sensibilização pelo tema. Os indivíduos atuantes nos equipamentos públicos, bem como aqueles associados, demonstram certo receio e insegurança quando se trata da compra por dispensa licitatória.

E ainda, muitas vezes, certas instituições relacionadas aos equipamentos, como empresas alocadas, realizam a escolha simplista de avaliar o produto pelo preço. E, nesse sentido, os agricultores familiares podem estar realmente em desvantagem, já que as dificuldades relacionadas à "logística" de abastecimento vivenciada atualmente (categoria também apontada pelos entrevistados $-\mathrm{n}=2$ ) podem culminar numa produção custosa para os pequenos agricultores, enquanto que as grandes indústrias agrícolas, por meio do mercado atacadista, oferecem produtos de menor qualidade, por um preço menor ainda. ${ }^{23}$

Outra categoria também apontada foi a "dificuldade de acesso a terra e a insumos" (n=2).

DSC: [...] Eu acho que essas questões dos insumos e da terra. A agricultura familiar tem menos terra e menos espaço. Tudo menos... menos incentivo, menos financiamento. Eu acho até que tem um bom nível de assistência técnica, que não estão sendo bem acessados. [...]

A dificuldade de acesso a terra e a insumos de produção decorre da pressão exercida pelo modelo hegemônico de produção, que domina o percentual de terras agricultáveis para uma produção monótona e pouco diversificada. Essa dificuldade de acesso a elementos fundamentais para a produção é encontrada em produções familiares de toda a América Latina, conforme apontado no estudo de Chiriboga (2002). ${ }^{7}$ 
As propostas

Diante da exposição de desafios, os entrevistados apontaram propostas de superação dos obstáculos. As categorias mais expressivas foram "organização de cooperativas/associações" (n=4) e "subsídios financeiros/fiscais/técnicos" (n=3). Ainda foram citados: "reforma agrária", "política de abastecimento pautada na agricultura familiar" e "reconhecimento da temática".

DSC: [...] Tem que ter uma organização pra que aqueles produtores consigam chegar, porque um produtor sozinho não consegue chegar no mercado. Ou os agricultores familiares avançam na sua organização econômica... as cooperativas ou elas avançam, ampliam sua base de associados ou formam centrais de cooperativas, complexificam a organização econômica ou não avançaremos. Eu acho que a melhor maneira é a orientação dentro de uma coisa mais organizada. E elaborar o Plano de Negócio, com a comunidade, pra saber o que plantar, onde vou vender, pra quem vender, que forma vender e por quanto, levando em consideração que o objetivo é fugir do atravessador, é produzir de forma sustentável, vender direto pro consumidor, garantir a Segurança Alimentar e o excedente servir pra garantir também a mesa de outras pessoas que não têm atividade produtiva. [...]

DSC: [...] Eu acho que acima de tudo évontade política... eu acho que prioridade política se traduz em recursos, em financiamento e gente pra trabalhar na Política, nas ações e o apoio da sociedade civil é fundamental, nesse sentido. Dar o apoio com capacitação técnica e com alguns insumos e com algum recurso, crédito... capacitação das famílias, levando em consideração a capacidade e o sistema de produção, a capacidade do que produz aquela terra e qual o tipo de cultura é mais rentável, mais adaptada àquela realidade. Se der condições das famílias produzirem, se der equipamentos e espaços, eu acho que eles têm condições de competir com os que vem de outro estado, teriam condições de atender a um preço abaixo do que é praticado hoje no mercado. [...]

\section{Para Maluf: ${ }^{24}$}

[...] os obstáculos e as principais demandas de apoio dos agricultores para implementarem empreendimentos nessa direção referem-se à sua organização, visando estimular o associativismo baseado em pequenos grupos, às técnicas de produção para aprimorar o processamento ou a transformação da matéria-prima à gestão dos empreendimentos nos seus componentes administrativo-contábil, mercadológico e financeiro.

É necessário incentivar a organização dos agricultores familiares em cooperativas ou associações econômicas, pois esta se torna uma forma de inserção competitiva no mercado. Afinal, essas organizações podem estar atuando no sentido de minimizar os custos de comercialização dos produtos, no custo de insumos, créditos, tecnologia e informação. Além desse aspecto, preservar a autonomia e a capacidade de gestão dos associados é fundamental para a articulação, tanto com 
o mercado de forma geral, como com o governo e as políticas de incentivo, a fim de estar sempre realizando a readequação das leis, caso necessário, e permitindo o adequado monitoramento social. ${ }^{7}$

A necessidade de incentivo fiscal, financeiro e técnico é apontada pelo estudo de Triches \& Schneider ${ }^{23}$ como um dos aspectos mais relevantes. Por meio da avaliação de várias entidades executoras do PNAE, identificou-se que aquelas que obtiveram sucesso, quanto à inserção da agricultura familiar na alimentação escolar, receberam auxílio relevante de entidades representativas como as de assistência técnica e de sindicatos rurais, que assessoravam e capacitavam os agricultores, ao passo que atendiam às necessidades das instituições públicas, de forma a propor ações que facilitassem o acesso desses produtores aos mercados.

\section{Conclusão}

O estudo permitiu identificar a íntima relação existente entre o conceito de Segurança Alimentar e Nutricional e a maioria dos indivíduos entrevistados. De forma geral, a visão dos entrevistados sobre tal conceito foi ampla e abarca de forma completa o entendimento, que vai desde a forma de produção até a condição de acesso físico do alimento, perpassando relações sociais, econômicas e, principalmente, a sustentabilidade.

Os sujeitos demonstraram tendências positivas à promoção de circuitos locais de produção, entendendo esse modelo produtivo como uma forma de se garantir SAN, trazendo à prática todas as dimensões conceituadas. Entretanto, essa reestruturação para um novo modelo hegemônico de produção é conquistada de maneira paulatina, fazendo-se necessário modificar, primeiramente, a cultura do sistema econômico, além de uma conscientização da comunidade para o tema.

No Distrito Federal, a inserção da agricultura familiar no mercado institucional, dos restaurantes comunitários e banco de alimentos deverá percorrer muitos obstáculos, mas que poderão ser superados com o apoio do governo local: estruturação e organização produtivas dos agricultores para atender às demandas institucionais; ações de sensibilização aos empresários atuantes nos equipamentos, junto a uma política de inserção da compra preferencial da agricultura familiar nos editais de licitação dos restaurantes comunitários; e oferta de infraestrutura local para escoamento mais eficiente da produção familiar.

O estudo aponta ainda o incipiente debate sobre a reestruturação de novos modelos produtivos descentralizados, principalmente na Região Centro-Oeste do país. O debate iniciado dentro da comunidade acadêmica e científica pode ser um catalisador para que a temática ganhe espaço e toque a comunidade, no sentido de discutir de forma participativa propostas de superação dos possíveis entraves vivenciados pela agricultura familiar no Distrito Federal. 


\section{Referências}

1. Castro J. Geografia da fome. O dilema brasileiro: pão ou aço. $8^{a}$ ed. Rio de Janeiro: Civilização Brasileira; 2008. 318 p.

2. Belik W. Perspectivas para segurança alimentar e nutricional no Brasil. Saúde Soc. 2003; 12:12-20.

3. Burity V, Franceschini T, Valente F, Recine E, Leão M, Carvalho MF. Direito humano à alimentação adequada no contexto da segurança alimentar e nutricional. Brasília: ABRANDH; 2010. 204 p.

4. Brasil. Lei no 11.346, de 15 de setembro de 2006. Cria o Sistema Nacional de Segurança Alimentar e Nutricional (SISAN) com vistas a assegurar o direito humano à alimentação e dá outras providências. Diário Oficial da União 18 set. 2006.

5. Brasil. Câmara Interministerial de Segurança Alimentar e Nutricional. Plano Nacional de Segurança Alimentar e Nutricional: 2012/2015. Brasília: MDS; Consea; 2011.

6. Brasil. Câmara Intersetorial de Segurança Alimentar e Nutricional do Distrito Federal. I Plano Distrital de Segurança Alimentar e Nutricional. Brasília: Sedest; Consea; 2013.

7. Chiriboga M. Desafios de la pequeña agricultura familiar frente a la globalización. Perspectivas Rurales 1997; (1):9-24.

8. Instituto Brasileiro de Geografia e Estatística. Censo agropecuário 2006: agricultura familiar primeiros resultados - Brasil, Grandes Regiões e Unidades da Federação. Rio de Janeiro: IBGE; 2006. p. 1-267.

9. Guanziroli CE. PRONAF dez anos depois: resultados e perspectivas para o desenvolvimento rural. Rev. Econ. Rural 2007; 45(02):301-328.

10. Vaitsman J, Paes-Souza R. Avaliação de Políticas e Programas do MDS: Resultados: Segurança Alimentar e Nutricional. v. I. Brasília: MDS/SAGI; 2007. 412 p.

11. Distrito Federal. Lei no 4.752, de 07 de fevereiro de 2012. Dispõe sobre a criação do Programa de Aquisição da Produção da Agricultura - PAPA/DF e dá outras providências. Diário Oficial do Distrito Federal 8 fev. 2012.

12. Brasil. Lei no 11.947, de 16 de junho de 2009. Dispõe sobre o atendimento da alimentação escolar e do Programa Dinheiro Direto na Escola aos alunos da educação básica; altera as Leis $\mathrm{n}^{\circ 1} 10.880$, de 9 de junho de 2004, 11.273, de 6 de fevereiro de 2006, 11.507, de 20 de julho de 2007; revoga dispositivos da Medida Provisória no 2.178-36, de 24 de agosto de 2001, e a Lei no 8.913, de 12 de julho de 1994; e dá outras providências. Diário Oficial da União 17 jun. 2009.

13. Belik W, Chaim NA. O programa de alimentação escolar e a gestão municipal: eficiência administrativa, controle social e desenvolvimento local. Rev. Nutr. 2009; 22(5):595-607.

14. Pereira MG. Epidemiologia: teoria e prática. Rio de Janeiro (RJ): Guanabara Koogan; 2003.

15. Minayo MCS. O Desafio do conhecimento: pesquisa qualitativa em saúde. $12^{a}$ ed. São Paulo: Hucitec; 2010. 407 p.

16. Rosa MVPFC, Arnoldi MAGC. A entrevista na pesquisa qualitativa: mecanismos para validação dos resultados. Belo Horizonte: Autêntica; 2008. 112 p. 
17. Lefèvre F, Lefèvre AM. O sujeito coletivo que fala. Interface - Comunic. Saúde Educ. 2006; 10(20):517-24.

18. Brasil. Ministério do Desenvolvimento Social e Combate à Fome. Marco de referência de educação alimentar e nutricional para as políticas públicas. Brasília: MDS; Secretaria Nacional de Segurança Alimentar e Nutricional; 2012.

19. Maluf RS. Ações públicas locais de abastecimento alimentar [Internet]. São Paulo-SP, Polis Papers: Polis Assessoria, Formação e Estudos em Políticas Sociais; 1999; (5):1-42.

20. Instituto Brasileiro de Geografia e Estatística. Pesquisa de orçamentos familiares 2008-2009: análise do consumo alimentar pessoal no Brasil. Rio de Janeiro: IBGE; 2011. 150 p.

21. Carneiro FF, Pignati W, Rigotto RM, Augusto LGS, Rizollo A, Muller NM, et al. Dossiê ABRASCO. Um alerta sobre os impactos dos agrotóxicos na saúde. $1^{\text {a }}$ parte. Rio de Janeiro: Abrasco; abr. 2012. 98 p.

22. Weathrell C, Tregear A, Allinson J. In search of the concerned consumer: UK public perceptions of food, farming and buying local. Journal of Rural Studies 2003; 19(2)233-244.

23. Triches RM, Schneider S. Alimentação escolar e agricultura familiar: reconectando o consumo à produção. Saúde e Sociedade, 2010; 19(4):933-945.

24. Maluf RS. Mercados agroalimentares e a agricultura familiar no Brasil: agregação de valor, cadeias integradas e circuitos regionais. Ensaios FEE 2004; 25(1):299-322.

25. Guilhoto JJ, Silveira FG, Ichihara SM, Azzoni CR. A importância do agronegócio familiar no Brasil. Rev. Econ. Sociol. Rural 2006; 44(03):355-382.

26. Starr A, Card A, Benepe C, Auld G, Lamm D, Smith K, et al. Sustaining local agriculture: barriers and opportunities to direct marketing between farms and restaurants in Colorado. Agriculture and Human Values 2003; 20:301-321.

Recebido: $24 / 10 / 2013$

Aprovado: 09/01/2014 
